\title{
Comunicación masiva - culturas tradicionales: un estudio sobre persistencia y transformación en las fiestas del pueblo de Conkal, Yucatán*
}

\author{
Roxana Quiroz Carranza** \\ Universidad Autónoma de Yucatán \\ Gretty Escalante Góngora*** \\ UNIVERSIDAD DEL MAYAB
}

Esta investigación tuvo como objetivo identificar lo que persiste y lo que se ha transformado en las fiestas del pueblo que se celebran en la localidad de Conkal, Yucatán, tanto en su componente festivo como religioso. Ocupa un lugar especial la búsqueda de la relación medios masivos de comunicación-culturas tradicionales a través de las tres principales fiestas del pueblo que se efectúan anualmente en Conkal.

La información proviene del conocimiento, intereses y prácticas que en torno a las fiestas del pueblo tienen los niños y niñas que acuden a las cuatro escuelas primarias de la localidad: la "Rafael Ramírez Castañeda", la "Margarita Maza de Juárez", la "Marcial Cervera Buenfil" y la "Rodolfo Menéndez de la Peña". Asimismo, de informantes claves de la comunidad y del trabajo etnográfico realizado por el equipo de investigación.

El estudio inició en mayo de 2004 y culminó en abril de 2006, lo que permitió indagar las tres fiestas que se celebran a lo largo de un año.

*La investigación fue realizada con recursos provenientes del Programa Fondo Mixto del CONACYT-Gobierno del estado de Yucatán y la Universidad del Mayab.

**Profesora-investigadora de la Facultad de Ciencias Antropológicas de la Universidad Autónoma de Yucatán.

***Profesora-investigadora de la Escuela de Comunicación de la Universidad del Mayab. 
En los periodos intermedios entre fiestas se realizaron las entrevistas a los informantes claves, se aplicaron diferentes técnicas de investigación con los niños y niñas de las escuelas primarias, y se obtuvo la opinión de sus respectivos profesores, así como los testimonios de padres o abuelos de los estudiantes que participaron en este estudio.

En el tiempo que duró la investigación se logró documentar aspectos de la fiesta del pueblo que han permanecido al paso de la historia, pero también muchos que han experimentado cambios por múltiples factores de tipo cultural, social, político y económico. Es precisamente en las transformaciones donde encontramos la presencia de los medios masivos de comunicación.

Es importante subrayar que los resultados de la investigación y las propuestas de la comunidad para preservar la esencia de las fiestas tradicionales se dan en un proceso de transición entre un modo de celebrarse y otro. Aún así, la reflexión desarrollada entre los niños y niñas, sus profesores y profesoras y los padres de familia, además del conocimiento que las autoridades municipales han tenido sobre los resultados arrojados por la investigación, permiten observar que hay propuestas claras para trabajar por la preservación y transmisión de los significados culturales de las fiestas del pueblo en las nuevas generaciones.

The Fiesta del Pueblo is a traditional cultural event of great importance in Yucateco Mayan communities, whose origin is in the colonial history of the region. The elements of the Fiesta del Pueblo and its organization have experienced transformation over the passage of time. Important studies on the subject point to changes in economic, social, and cultural phenomena, such as trade, tourism, urbanization, modernization, and secularization. Today, the influence of mass communication has been added to this picture.

In order to know what remains the same and what has been transformed within the traditional celebrations of Conkal, Yucatan, and with the hope of contributing to their preservation, a study was performed by a number of contributors, whose principle subjects of investigation included children studying in the four local primary schools. In addition, their professors, parents, grandparents, and a number of key local informants participated.

Furthermore, the influence of mass communication was studied in modern representations and cultural practices within these events, particularly between children. In order to obtain the necessary information, the following qualitative and quantitative investigative techniques were used: interviews, ethnographic observation, drawing interpretation, theatrical performance, photo records, video records, and surveys. In order to receive proposals advocating the essential preservation of the Fiesta del Pueblo in 
its various forms, group discussion and participation was initiated between professors and parents alike.

The results of the investigation indicate that the celebration of Fiesta del Pueblo in Conkal, with its festive and religious flavor, has not only persisted over the passage of time, but also continues to be recognized by new generations as a traditional cultural event with which the community can identify itself. This leads to the conclusion that the Fiesta del Pueblo has indeed survived strong pressures at a cultural, economic, political, and social level, even in the face of colonial domination and western modernity and globalization.

Nevertheless, these celebrations still display practices and contemporary cultural symbols in new ways, such as mass communication. These new practices and symbols are expressed in the preferences of children for mechanical games like the "Oriental Dragon," videogames, and parties that include ambient light and sound, modern musical rhythms like English Pop and rock music, and new styles of dancing. But the results still show that the parents, teachers, siblings, and friends are important learning influences with respect to dance, in addition to television and cinema personalities.

\section{INTRODUCCIÓN}

Las culturas tradicionales de los pueblos indígena-campesinos de nuestro país, y por tanto de Yucatán, han sido estudiadas desde diversas posiciones. Están quienes sostienen que a éstas no les ha llegado la modernización, y por tanto permanecen estáticas, enclavadas en el pasado. Martín Barbero (1987, p. 13) señala que quienes estudian lo indígena como una identidad que no cambia, la colocan en un pasado mítico, fuera de la dominación y de la historia.

Desde otros enfoques se afirma que todas las culturas cambian permanentemente: "el cambio es su forma de ser" (Bonfil, 1993, p. 229). Por tanto, se considera que todas las culturas actuales (tradicionales o no) son modernas, porque cada una de ellas ha sabido ajustarse a sus circunstancias históricas. También se reconoce en lo indígena su carácter de culturas dominadas, aunque poseedoras de una existencia positiva a desarrollar, donde lo que importa es conocer la forma en que sobreviven siendo parte de la modernidad y cómo son capaces de producir y desarrollarse como culturas, de afirmarse étnicamente (Martín Barbero, 1987, p. 13).

El antropólogo Guillermo Bonfil considera que algunas culturas (las dominantes) han actualizado su manera de imponerse a otras, y otras (las subalternas

Comunicación masiva - culturas radicionales: • 381 un estudio sobre persistencia y transformación en las fiestas del pueblo de Conkal, Yucatán 
o dominadas) han actualizado sus respuestas, "desde las formas de rebelión hasta los modos de apegarse a su tradicionalismo y recrear su propio universo significativo" (1993, p. 230). A partir de estas ideas y otras producidas desde los años 80 , se enuncia la posibilidad real de que los pueblos indígenas-campesinos se transformen como actores dinámicos que forman parte de sociedades modernas y complejas, sin renunciar a su identidad contrastante. De igual forma, es posible situar su existencia actual no como producto de la continuidad milenaria sino de las múltiples adaptaciones y refuncionalizaciones a la cambiante realidad colonial y nacional (López y Rivas, 2005).

Una perspectiva de esta naturaleza nos permite entender lo que ha acontecido con las fiestas y danzas tradicionales en Yucatán, que aparecen indisolublemente unidas en lo que desde las propias comunidades se denomina "la fiesta del pueblo", como expresiones de una identidad que ha logrado mantener viva parte de las raíces culturales del pueblo maya yucateco, sin omitir su condición de cultura dominada (Bartolomé, 1988) y sin negar las transformaciones experimentadas.

De ahí que observemos hoy día, al igual que Miguel Bartolomé hace dos décadas, la vigencia del idioma maya en múltiples pequeñas comunidades, diversas prácticas culturales tradicionales (como las fiestas del pueblo) y la conservación de una cierta conciencia social o, en su defecto, de una identidad étnica asumida como estigma, actuando todos ellos como componentes de esa identidad.

En Yucatán, como en otros estados de la República Mexicana, existen desde hace décadas e incluso siglos, costumbres y tradiciones que identifican y distinguen a las comunidades que desde la otredad denominamos maya-yucatecas, aunque no siempre exista una identidad étnica asumida explícitamente por ellas. Una de las tradiciones más antiguas que hasta nuestros días se practica en los diferentes municipios del estado es la fiesta del pueblo.

Esta celebración como su nombre lo indica, es una fiesta en la cual se realizan diversas actividades religiosas y paganas en honor de un santo patrón o un símbolo sagrado y cuyo origen lo encontramos en la historia colonial de la región y en la fusión de prácticas, símbolos y significados procedentes de raíces indígenas y españolas (Redfield, 1944; Irigoyen, 1973; Quintal, 1993; Fernández y Quintal, 1992). Con el paso el tiempo estas celebraciones se han ido transformando y adaptando a las necesidades, propósitos y características de cada comunidad situada en contextos socio-históricos específicos.

La antropóloga Fanny Quintal (1993, p. 5) plantea que a través de las fiestas patronales, organizadas desde un catolicismo popular que sigue vigente entre 
los mayas yucatecos, con sus procesiones, misas, gremios, vaquerías, corridas de toros, bailes populares y ferias, es posible vislumbrar el tipo de sociedades que las generan, recrean y transforman, es decir, les dan vida. Así, un acercamiento a las fiestas del pueblo de Conkal, Yucatán, ubicado a unos $13 \mathrm{Km}$. de Mérida, capital del estado, propicia no sólo conocer y reconocer la identidad y cultura de esta localidad, sino comprender los procesos de persistencia y transformación que viven sus festejos tradicionales y con ellos la propia comunidad.

De acuerdo con Fernández Repetto (1990) y con la revisión bibliográfica realizada, se puede afirmar que poco se ha escrito sobre las fiestas y danzas de Yucatán, como expresiones de una identidad étnica. De manera complementaria al objetivo central de sus estudios, Redfield, Villa Rojas y Thompson "son algunos de los que mencionan ciertos rasgos particulares de este tipo de celebraciones religiosas" (Fernández, 1990, p.21), a los que se suman los trabajos de Irigoyen (1973), Maas Collí (1983; 1991; 1995), Quintal (1992; 1993), el propio Fernández Reppeto (1990; 1992), Pérez Sabido (1983) y Negroe Sierra, como los más representativos.

Si escasos trabajos hay acerca de las fiestas del pueblo en la región, prácticamente no existen los que se hayan preocupado por estudiar la relación entre comunicación masiva y cultura tradicional, como eje principal. Asimismo, los estudios sobre las fiestas y danzas tradicionales que se han realizado en Yucatán, han tomado como principal punto de referencia la acción de los adultos y jóvenes que habitan en las comunidades donde se celebran, quedando en segundo plano la presencia infantil.

Esto último resulta interesante frente a las observaciones de Gardner (en Villanueva, 2000, p. 25), quien opina que las primeras concepciones que se forman en los nińos no se erradican, sino que permanecen en la memoria, ocupando una posición subalterna frente a nuevas concepciones.

Este escenario nos llevó a establecer como preguntas de investigación, las siguientes. En la forma de practicar y celebrar las fiestas y danzas tradicionales en Conkal: ¿Qué rasgos han perdurado a través del tiempo? ¿Qué transformaciones han experimentado? ¿Cómo las viven y se las representan los niños y niñas de la localidad? ¿Qué relevancia tienen en sus vidas cotidianas? ¿Cuánto han influido los medios masivos de comunicación en las transformaciones y representaciones actuales?

Por tanto, los objetivos que guiaron este trabajo de investigación fueron por un lado, identificar aquellos elementos simbólicos que perduran hasta nuestros días, es decir, que han podido transmitirse de generación en genera-

Comunicación masiva - culturas radicionales: $\bullet 383$ un estudio sobre persistencia y transformación en las fiestas del pueblo de Conkal, Yucatán 
ción a los niños y las niñas de Conkal, Yucatán, respecto de las fiestas y danzas tradicionales que se realizan y practican en su localidad. Por otro, ubicar las transformaciones que han experimentado estas fiestas y danzas, a partir de las percepciones y prácticas culturales de los niños y niñas estudiados. Un tercer punto fundamental fue identificar todas aquellas manifestaciones que revelaran una relación entre los medios masivos de comunicación y las prácticas culturales relativas a las fiestas y danzas.

\section{Metodología}

Este conjunto de reflexiones nos llevó a elegir a los niños y niñas de Conkal como los principales más no únicos sujetos de investigación. El acceso a ellos se logró a través de las cuatro escuelas primarias de la localidad: la "Rafael Ramírez Castañeda”, la "Margarita Maza de Juárez", la "Marcial Cervera Buenfil”, y la "Rodolfo Menéndez de la Peńa". El estudio contó con la participación de 670 alumnos en total, que cursaban de primero a sexto grado de primaria. La elección de los niños y niñas en un rango de 6 a 14 años de edad, se debe a que son fuertes receptores de nuevas manifestaciones culturales y altos consumidores de medios de comunicación, pero el proceso de socialización primaria aún está fuertemente sellado por la familia, la escuela, la iglesia y la comunidad.

Hoy Conkal cuenta con una población en este rango de edad de 1,067 habitantes, de los cuales 1,025 asisten a la escuela, espacio que ofreció condiciones muy favorables para la realización del estudio, ya que congregó a todos los sujetos durante el ciclo escolar 2004-2005 para la aplicación de las diferentes técnicas de investigación.

Los niños y niñas de Conkal por las mismas circunstancias culturales y el espacio geográfico donde se desenvuelven, presentan características que son necesarias mencionar en nuestro estudio tales como su inmersión temprana en los trabajos del padre o de la madre, la influencia en la forma de vestir y de hablar de los hermanos mayores, el reducido tiempo que ellos le dedican a la escuela en comparación con otras actividades que realizan y la limitada variedad de formas de entretenimiento que poseen. Estas características hacen que además de la forma de comportamiento y crecimiento habitual, vivan de una forma muy particular las fiestas tradicionales de su pueblo.

El estudio realizado se sustenta en una metodología de corte cualitativo, elegido por razones epistemológicas y por las propias características de la indagación. A partir de esta decisión, en el diseño de la investigación se renunció al uso de 
hipótesis y se consideraron las preguntas y objetivos como el punto de partida de un procedimiento que buscó no probar sino comprender e interpretar.

Para la reconstrucción histórica de las fiestas del pueblo que permitiera conocer lo que perdura y se ha transformado se usó la entrevista estructurada, que realizaron los propios nińos y niñas a sus padres o abuelos, y la entrevista en profundidad efectuada por el equipo de investigación a informantes claves de la comunidad, dada la carencia de fuentes documentales sobre el tema. Para elaborar la etnografía de la festividad y detectar los referentes mediáticos visibles presentes en ella se desarrolló la observación participante. Para explorar los conocimientos y prácticas de los niños y las niñas en torno de las fiestas y danzas, así como los elementos culturales provenientes de los medios de comunicación que pudieran estar influyendo en dichos conocimientos y prácticas, se usaron diversas técnicas como las representaciones teatrales, el registro fotográfico, el dibujo, la selección de fotografías y el cuestionario.

\section{CONKAL Y SUS FIESTAS DEL PUEBLO}

Conkal, Yucatán, es la cabecera del municipio del mismo nombre. Se trata de una pequeña localidad muy próxima a Mérida, conformada por un poco más de 6 mil habitantes (INEGI, 2001). Se ubica en lo que hace más de una década se identificaba como la zona henequera. Hasta tiempos recientes se caracterizó, principalmente, por un desarrollo agropecuario, una población rural predominante y múltiples prácticas culturales tradicionales. Su creciente dependencia con las actividades industriales, comerciales y de servicios que ofrece la capital del estado, la fuerte presencia de los medios de comunicación en la vida cotidiana, así como el uso de nuevas tecnologías han transformado de muy diversas formas sus modos de vida. De acuerdo con INEGI (2001), el $85.2 \%$ de las viviendas particulares habitadas disponen de radio o radiograbadoras; el $92.1 \%$ de televisores; el $26.7 \%$ de videocaseteras; el $14.4 \%$ de teléfono, y el $2.3 \%$ de computadoras.

En este Conkal contemporáneo se celebran anualmente tres fiestas del pueblo. Esto se debe a diversos motivos económicos, políticos y religiosos. En 1973, Irigoyen mencionaba en su calendario de fiestas tradicionales de Yucatán, que la fiesta del pueblo de Conkal era en honor de la Santa Cruz. Sin embargo, la observación participante permitió saber que hoy día se llevan a cabo tres fiestas: la de la Santa Cruz, la de la Inmaculada Concepción y la de San Francisco de Asís.

Comunicación masiva - culturas radicionales: $\bullet 385$ un estudio sobre persistencia y transformación en las fiestas del pueblo de Conkal, Yucatán 
La fiesta de la Santa Cruz, o como comúnmente se le conoce en el pueblo: la fiesta en honor al Cristo del Gran Poder, se efectúa a partir del 25 de abril hasta el 3 de mayo. En este lapso, se celebra tanto la parte religiosa como la profana. Aunque la fiesta de la Santa Cruz aún conserva ciertos elementos distintivos que la caracterizaron en sus tiempos de esplendor y auge, según los informantes claves, ya no es esa celebración majestuosa que recuerdan las personas mayores, sino que se ha reducido a la realización de la "ramada", una misa, la novena y algún baile de luz y sonido, casi todo llevado a cabo en un espacio privado (la casa de los custodios de la Santa Cruz), participando un reducido número de personas entre niños, jóvenes y adultos.

Por su parte, la fiesta de la Inmaculada Concepción, aunque originalmente debe celebrarse el 8 de diciembre, surge por iniciativa de un sacerdote del pueblo como una fiesta en el mes de mayo para "competir" con la fiesta del Gran Poder, ya que ésta no era organizada directamente por alguna autoridad civil o religiosa, sino que estaba en manos de una familia de la comunidad. Al promoverse la celebración directamente por el sacerdote de Conkal, este festejo empezó a cobrar fuerza hasta convertirse en la principal fiesta del pueblo en la cual se pueden encontrar, aunque con múltiples transformaciones, prácticamente todos los elementos que integran una fiesta tradicional. Hoy se celebra del 7 al 10 y del 22 al 29 de mayo.

En cuanto a la fiesta en honor de San Francisco de Asís, ésta se realiza del 4 al 11 de octubre y es una fiesta muy pequeña, ya que sólo la organiza y participa un gremio (el de los palqueros ${ }^{1}$ ), y está constituida por corridas de toros, una feria modesta, una procesión y bailes de luz y sonido. Surge en 1985 por iniciativa del entonces presidente municipal y fundador del gremio "Hijas de María", para rescatar la imagen del santo patrono que históricamente corresponde a la localidad, cuyo convento fue fundado por la orden de los franciscanos en tiempos de la Colonia.

\section{COMPONENTES TRADICIONALES Y CONTEMPORÁNEOS DE LA FIESTA DEL PUEBLO}

Para entender el contexto de la fiesta del pueblo como unidad de análisis, es importante describir brevemente las actividades y los elementos que la integran

${ }^{1}$ El gremio de los palqueros son los responsables de construir los palcos y el coso taurino donde se celebra la corrida de toros. Como elemento característico, para la construcción no utilizan clavos, sino sólo amarres. 
hoy día, contrastando aquellos aspectos que han cambiado o han desaparecido, así como los que permanecen al paso del tiempo. El festejo, y por ende el inicio de la fiesta del pueblo, es el día en que de acuerdo con el calendario de la Iglesia Católica se recuerda al santo patrono, cuyo nombre porta la iglesia o capilla del lugar, aspecto que no se sigue de forma ortodoxa en Conkal.

La tradicional fiesta del pueblo tiene actividades religiosas y paganas. Como se indicó en párrafos anteriores, la forma de celebrar la fiesta del pueblo ha cambiado a través del tiempo, más en unas comunidades que en otras; sin embargo, entre las actividades religiosas aún se encuentran los gremios, las misas, las novenas y las procesiones en honor al santo patrono y entre los festejos paganos están las corridas de toros, las vaquerías, los bailes y la feria. Para efectos de este artículo, se describen a continuación las actividades más significativas para la comunidad.

Los lugares en donde se llevan a cabo las actividades religiosas son diferentes a la parte profana (Quintal, 1993). Así, el templo, el atrio de la iglesia y las calles inmediatas son el lugar de lo sagrado, mientras que la plaza, el palacio municipal y el lugar donde se coloca el ruedo, son áreas para lo profano, aunque por las dimensiones del pueblo están muy próximas unas de otras.

Los gremios son asociaciones que hacen su aparición los días de fiesta y otras fechas religiosas celebradas por la iglesia local y/o regional. La mayoría están organizados por oficios, género y edad, así que, dependiendo de la comunidad de la que se trate, podemos encontrar distintos gremios, como por ejemplo el de los palqueros, horticultores, niños, jóvenes, etc.

El día indicado para cada gremio, los socios y sus familias se reúnen en la casa del presidente o encargado del gremio. A determinada hora, cargan los emblemas de su organización: escudo, estandartes y pabellones y se dirigen a la iglesia acompañados de la orquesta y el sonido de los voladores. Al llegar, depositan en el altar sus emblemas, rezan un rosario o participan en la misa y se retiran a sus casas. Al día siguiente, los socios se dirigen de nuevo al templo, toman del altar los emblemas de su organización y se trasladan a la casa del próximo presidente del gremio en donde comen, beben y realizan la asamblea para el cambio de directiva. Así concluye el desempeño de la mayoría de los gremios.

En cuanto a las procesiones, éstas se realizan el día dedicado al santo patrono y en ellas participan los integrantes de los gremios, los visitantes, los devotos y el público en general. Concluida la procesión, el santo patrono es puesto al alcance de los creyentes que se acercan para depositar una limosna o rezar una oración, dentro de la iglesia.

Comunicación masiva - culturas radicionales: $\bullet 387$ un estudio sobre persistencia y transformación en las fiestas del pueblo de Conkal, Yucatán 
Para hablar de la parte festiva, hay que explicar en principio el concepto de vaquería. Esta es una especie de baile popular en donde hombres y mujeres se reúnen para ejecutar la jarana, danza tradicional de Yucatán, durante toda la noche. Las mujeres asisten vestidas de vaqueras, es decir, con el terno, la joyería correspondiente y llevando en la cabeza un sombrero adornado con flores y/o cintas. Los hombres en cambio, llevan su tradicional guayabera blanca, pantalón blanco, pañoleta roja y sus alpargatas chillonas. Actualmente aunque algunos hombres y mujeres aún siguen portando los atuendos para esa ocasión, muchos asisten únicamente a mirar cómo bailan todas las parejas y premiar con sus aplausos a los diestros bailadores, pero no participan activamente.

En lo referente a las corridas de toros, el proceso inicia con la construcción del ruedo taurino a cargo de los palqueros. Se levanta el tablado de diferentes niveles formado por troncos, bejucos, palmas, o en su caso láminas de cartón pero sin utilizar un sólo clavo, todo se hace a través de amarres.

Las corridas por lo general inician con las notas de un paso doble a cargo de la orquesta y un paseo que realizan los toreros y banderilleros por todo el ruedo. Cabe mencionar que en las fiestas tradicionales que estamos describiendo las corridas no son como las que vemos en las grandes ciudades. Regularmente son momentos muy divertidos y emocionantes pues dado su carácter informal, nunca falta un atrevido o pasado de copas que se lance al ruedo para torear y termine con tremendo susto frente al toro. Los toros que hoy se utilizan son de lidia; estos se rentan y son muy costosos, por lo tanto, únicamente se suele matar al primer toro de la tarde, el cual es procesado en las afueras del ruedo para su venta al término de la corrida. Con esta carne se realiza el guiso conocido como chocolomo.

Los bailes y las ferias, por su parte, son actividades que se realizan casi siempre en el centro de poblado, cuyo esplendor se observa por las noches. Los bailes por lo regular son amenizados por conjuntos de cumbias y empresas de luz y sonido. A estos bailes asisten todo tipo de personas de la comunidad e incluso de las poblaciones cercanas.

Persistencia Y TRANSFORMACión EN LA FIESTA DEL PUEblo DESDE LA LITERATURA

La obra clásica de Robert Redfield, Yucatán: una cultura en transición, (editada en español en 1944), aporta valiosa información sobre las fiestas pagano religiosas de diferentes puntos del estado. En ésta, el autor habla de las "pérdidas" 
y las "transformaciones" de este "suceso periódico y principal en la vida de cada comunidad local de Yucatán" (p. 324). Entre los factores que menciona están los intereses mercantiles de particulares y políticos que hicieron de las fiestas un sustantivo negocio; los forasteros o turistas que acudían a los festejos en busca del "folclore"; la influencia urbana e incluso la europea a través de las clases medias y altas que veraneaban en las costas yucatecas por razones de "moda" y las vías de comunicación (trenes y carreteras) que hicieron posible viajar a casi todos los puntos del estado. Así, "la secularización destruyó los viejos significados" (p. 361).

Renán Irigoyen, en su Calendario de fiestas tradicionales de Yucatán (1973), al hablar de "desapariciones" hace una diferencia entre las fiestas tradicionales organizadas como atractivo turístico y aquellas donde "la fiesta ha conservado su pureza y espontaneidad" (p. 5). A estas últimas las sitúa en las poblaciones pequeñas y alejadas de Mérida. De manera explícita, ubica la influencia del turismo como un factor de "pérdida", junto con los grupos de rematadores de las principales fiestas populares y carnavales del interior del estado, los intereses de los abastecedores o comerciantes de ganado, los que quieren organizar los bailes populares, las organizaciones gremiales y los que construyen los palcos del coso taurino mediante pago.

Alfonso Villa Rojas, en su obra Los elegidos de Dios (1978), documenta su regreso al cacicazgo de X-Cacal, refugio de los indígenas insurrectos en la Guerra de Castas, 40 años después de su investigación etnográfica sobre los mayas de Quintana Roo, para encontrarse con cambios espectaculares que se habían producido en las comunidades indígenas objeto de su estudio. Esas transformaciones culturales también eran visibles en el campo de las prácticas del catolicismo popular. Así, carreteras asfaltadas, caminos vecinales de grava, el proceso educativo, la expansión del protestantismo y el catolicismo, la urbanización, los nuevos incentivos económicos, entre los elementos más importantes, penetraron inexorablemente y debilitaron sus modos tradicionales de vida.

Sólo Hilaria Maas Collí en su informe final de investigación titulado "La religión y símbolos sagrados en la vida cotidiana de las familias campesinas, Huhí, Yucatán" (diciembre de 1995), aborda el tema de las repercusiones de la televisión en las prácticas religiosas y en los símbolos sagrados dentro del hogar, trabajo que toca un aspecto de nuestro interés, pero lejos del contexto de las fiestas del pueblo, objeto de esta investigación.

Así, desde la perspectiva de estos estudiosos, son factores económicos, sociales y culturales como la mercantilización, el turismo, la urbanización,

Comunicación masiva - culturas radicionales: $\bullet 389$ un estudio sobre persistencia y transformación en las fiestas del pueblo de Conkal, Yucatán 
la modernización y la secularización en los que recae el peso principal de las transformaciones experimentadas en las fiestas del pueblo, a lo que se añade hoy día la influencia de los medios masivos de comunicación.

Como se indicó líneas arriba, en nuestra investigación ocupa un lugar fundamental el estudio de la relación medios masivos de comunicación-cultura tradicional. Hoy día no sería posible entender las transformaciones operadas en las culturas tradicionales, en los últimos 50 años, sin tomar en consideración el papel que están desempeñando los medios y los procesos de comunicación de masas (Martín-Barbero, 1999). Importantes contribuciones teóricas al respecto han hecho Martín Barbero, García Canclini y Renato Ortiz, a partir de sus análisis de las culturas populares, la comunicación masiva, la relación campo-ciudad y la modernidad.

Resulta importante establecer como punto de partida que la comunicación masiva juega hoy día un papel central en la cultura moderna, ya que la modifica constantemente (Thompson, 1991). Tal y como lo señala Thompson, los diversos medios de comunicación tienen un papel de gran importancia en nuestra vida cotidiana, pues nos ofrecen un flujo constante de información y conocimiento, tal y como se aprecia en el Conkal contemporáneo.

De acuerdo con García Canclini (1990), los nexos entre los medios de comunicación y las culturas populares tradicionales "forman parte de estructuras más amplias de interacción social”, desde las cuales los sectores populares organizan el sentido en el contexto de sus vidas cotidianas. En el caso del pueblo de Conkal hay que considerar no sólo la irrupción de las nuevas tecnologías comunicativas en la vida comunitaria, sino también los movimientos migratorios de ida y vuelta; la cercanía y el contacto permanente con la capital del estado desde tiempos coloniales; el contexto socio-histórico, es decir, "el proceso de apropiación y control cultural, político y económico al que estuvieron sujetos los pueblos indios, primero a mano de los conquistadores y colonizadores espańoles y luego por la acción de la oligarquía yucateca europeizada" (Fernández y Quintal, 1992, p. 43), así como su relación con las culturas globalizadas, entre otros aspectos altamente significativos.

El autor también plantea que las tecnologías comunicativas y la reorganización industrial de la cultura no sustituyen las tradiciones, ni masifican homogéneamente a los habitantes de las pequeñas comunidades, sino que cambian las condiciones de obtención y renovación del saber y la sensibilidad; proponen otro tipo de vínculos de la cultura con el territorio; de lo local con lo global; "otros códigos de identificación de las experiencias" (1990, p. 244). 
Por su parte, Martín Barbero (1987) nos propone alejarnos de los falsos dualismos, entre ellos el que opone el campo a la ciudad, lo popular a lo masivo, que podrían conducirnos a desconocer los "mestizajes", las complicidades y contradicciones que permean la "conexión" entre lo popular y lo masivo. Nos invita a dotarnos de un concepto de cultura "que haga posible pensar la mediación histórica” (p. 16) y que permita entender las fiestas de Conkal desde la modernidad.

Nos sugiere reconceptualizar lo indígena desde el espacio político y teórico de lo popular, que nos lleva a identificar lo tradicional-popular con lo subalterno, pero también con las resistencias intrínsecas, espontáneas, que lo subalterno opone a lo hegemónico (Martín Barbero, 1988), ya que así es posible el análisis de las condiciones sociales de producción del sentido, el análisis de las luchas por la hegemonía.

En cuanto a Renato Ortiz (1998), su reflexión sobre las culturas populares en el contexto de la modernidad-mundo, nos permite apreciar que esa cultura mundializada nos acompańa en "todos" los lugares. Y en esa modernidad-mundo, la distancia deja de ser un obstáculo físico para el desplazamiento, aspecto en el que los medios de comunicación tienen un papel preponderante.

Persistencia y transformación en la Fiesta del pueblo DESDE LOS ACTORES SOCIALES

Tal y como se estableció en el proyecto que ha guiado esta investigación, son tres los ejes indagados: lo que persiste, lo que se ha transformado y la influencia de los medios masivos de comunicación en las transformaciones y nuevas representaciones sobre las fiestas del pueblo.

\section{Lo que persiste}

La celebración de la fiesta del pueblo en Conkal, con su estructura festiva y religiosa, ha persistido al paso del tiempo y hoy sigue siendo reconocida al interior de la comunidad como una manifestación de su cultura tradicional, sin que esta valoración se vea afectada por los cambios o transformaciones enunciadas principalmente en los testimonios de los informantes claves y de los padres y abuelos de la localidad.

Los niños y niñas que asisten a las escuelas primarias identifican en la fiesta del pueblo una celebración propia de su comunidad, que los entusiasma y divierte año con año, aunque no siempre tengan claro en honor de quién se

Comunicación masiva - culturas radicionales: $\bullet 391$ un estudio sobre persistencia y transformación en las fiestas del pueblo de Conkal, Yucatán 
celebra. A partir de las técnicas de investigación utilizadas, las cuales estuvieron acompañadas por una actividad introductoria para sensibilizar a los niños y niñas en torno del tema de investigación, encontramos que ante la pregunta ¿en honor de quién son las fiestas del pueblo?, sus respuestas fueron o bien el silencio, o nombrar al presidente municipal, los héroes patrios, confundirlas con otra festividad como el Carnaval, aunque siempre hubo quien aportara la respuesta correcta. Dos posibles razones pueden inicialmente explicar la situación: una falta de transmisión de cierto conocimiento tradicional de padres a hijos, o la aparición de nuevas prácticas religiosas entre los habitantes de la localidad, en las que no se requiere un saber sobre las fiestas del pueblo propio del catolicismo popular.

Los componentes religiosos (gremios, procesiones, misas y novenas) y festivos (vaquería, corrida de toros, feria y bailes) continúan siendo la forma constitutiva de las fiestas del pueblo. Los testimonios de los informantes clave y de padres y abuelos documentan muy bien la forma de celebración en la perspectiva de los últimos 50 años, mientras que los niños y niñas describen la situación actual. Formalmente, hay puntos de convergencia entre ambas miradas, en particular sobre la estructura de la fiesta, sin embargo, ésta es percibida de forma diferenciada por las viejas y nuevas generaciones, ya que el discurso de las primeras hace referencia constante a las "pérdidas", a los "cambios", mientras que las segundas hablan de sus vivencias y disfrutes sin recurrir a un proceso comparativo con el pasado.

A través de los múltiples datos obtenidos por medio de las técnicas utilizadas, destaca que la parte festiva o profana de la fiesta de Conkal es más atractiva que la religiosa para la población en general, fenómeno común a muchas fiestas que se celebran en la región y ya registrado en diversos estudios sobre el tema. De manera que este hecho debe considerarse como una persistencia en la fiesta del pueblo. En el caso de los niños y niñas de las escuelas primarias, sus respuestas se centran de forma abrumadora en la corrida de toros, actividad festiva por naturaleza. Se puede afirmar que para ellos, éste es el símbolo de la fiesta de su pueblo.

De las tres fiestas que se celebran en Conkal, es importante reconocer que la de la Santa Cruz o la del Gran Poder de Dios es la que conserva el mayor número de elementos tradicionales, característicos de las fiestas del pueblo, tal y como se documenta en la literatura especializada. Sin embargo, es la fiesta donde las contradicciones religiosas y políticas se han visto agudizadas, de acuerdo con los testimonios de los informantes claves.

392 - Roxana Quiroz Carranza, Gretty Escalante Góngora 
Aún con los cambios que han experimentado las fiestas y que se señalan más adelante, es importante destacar que éstas han sobrevivido en medio de conflictos entre autoridades políticas y religiosas y los intereses comerciales existentes al interior de Conkal desde hace más de medio siglo, derivados de la organización primero de una y luego tres fiestas, como lo expresan los informantes claves. Estas contradicciones, intereses y cambios han afectado la forma de la celebración y muchos de los elementos constitutivos de las mismas, pero la esencia de las fiestas ha perdurado en circunstancias históricas difíciles.

\section{Lo que se ha transformado}

Un primer cambio notable es la celebración de tres fiestas del pueblo a lo largo de un año en Conkal, como resultado de las contradicciones o choque de intereses entre autoridades civiles y religiosas y particulares. El impacto más visible al seno de la comunidad es que ésta ha tenido que negociar en el marco de sus creencias religiosas la mayor o menor representación de los símbolos homenajeados. En poco más de 50 años han tenido que celebrar a la Santa Cruz (símbolo primigenio), a la Inmaculada Concepción (cuando ésta se festeja en diciembre) y a San Francisco de Asís (el patrono de Conkal) bajo argumentos no necesariamente de tipo histórico o por necesidades derivadas de las prácticas culturales de la comunidad.

Otro cambio importante está relacionado con el uso del espacio para la celebración de las fiestas. Históricamente, se han realizado en el centro del poblado donde se congregan los edificios que representan los poderes civiles y religiosos. Quintal (1993) ha explicado a detalle cómo de manera diferenciada los espacios que se destinan a las actividades religiosas no son los mismos que para la parte profana, aunque dadas las dimensiones del pueblo están muy próximos unos de otros, lo que permite que se conserve como una unidad.

Sin embargo, a partir de mayo de 2005, por disposición del Ayuntamiento de Conkal, la parte festiva pasó a realizarse en un área de grandes dimensiones a las afueras del poblado, decisión que ha establecido una importante distancia geográfica entre ambos momentos de la fiesta del pueblo y que ha generado descontento en el gremio de los palqueros, la comunidad y la parroquia. Dado que el hecho es reciente, las repercusiones socioculturales aún no se expresan claramente y el problema se ubica por el momento a nivel de "malestar social"; pero es de suponerse que esta decisión "política" acentuará mucho más la distancia entre lo festivo-lúdico y lo religioso, que ya de por sí revela la investigación.

Comunicación masiva - culturas radicionales: $\bullet 393$ un estudio sobre persistencia y transformación en las fiestas del pueblo de Conkal, Yucatán 
Diversos rasgos de las fiestas del pueblo se han perdido al paso de los años, particularmente elementos simbólicos claves de raíz indígena como la siembra del ceibo, árbol sagrado de los mayas, en el centro del ruedo durante las corridas de toros y otros como el baile de la cabeza de cochino en las vaquerías y la celebración de la "ramada" o "ramillete ${ }^{2}$ ". La recuperación de estos elementos simbólicos en la fiesta actual no ha sido promovida por ningún grupo involucrado en su organización, aunque los informantes claves y la literatura especializada hagan referencia constante de ellos y les atribuyan un alto valor cultural.

Una fuente importante de información para ubicar las transformaciones experimentadas en las fiestas del pueblo fueron las 123 entrevistas realizadas por los niños y niñas, de quinto y sexto grado, a sus padres o abuelos a través de una guía de cinco preguntas: ¿Cómo eran las fiestas del pueblo cuando ellos eran niños? ¿Cómo eran las vaquerías? ¿Cómo eran los gremios? ¿Cómo eran los bailes? Y ¿Cómo eran las corridas de toros?

Las entrevistas indican la desaparición de ciertas prácticas culturales asociadas a las fiestas del pueblo como la utilización de música en vivo en los bailes interpretada por orquestas famosas (hoy cambiada por luz y sonido), acudir a los bailes para bailar (hoy se va a mirar, a emborracharse y echar relajo), la convivencia familiar y comunitaria y la inclinación cada vez mayor por la parte festiva o profana de la fiesta.

En cuanto a la vaquería, los padres o abuelos destacan que asistía la población mestiza $^{3}$ con sus ropas tradicionales de gala y los muchachos invitaban a bailar a las muchachas, aspectos que han ido desapareciendo paulatinamente.

Asimismo, observan cambios en el concepto de la corrida de toros, hoy más espectáculo, más "bufa" que fiesta brava. El número de toros ofrecidos en promesa o sacrificados en el ruedo ha disminuido; en el segundo caso particularmente por el costo del animal. También recuerdan que para las corridas se utilizaban toros buenos, grandes y bravos, no "jugueteados" como ahora, y los toreros no se dedicaban sólo a las "charlotadas"; antes toreaban, entraban a matar.

La parte festiva también experimenta un proceso de "folklorización", entendido como espectáculo basado en tradiciones pero susceptible de comercia-

\footnotetext{
${ }^{2}$ Durante el baile que cerraba los festejos, se entregaba una cabeza de cochino ricamente adornada a los organizadores de la fiesta del año siguiente como símbolo de la transferencia de la responsabilidad. Un significado parecido se le atribuye a la "ramada" o "ramillete", aunque ésta es un cilindro adornado y relleno de diversos productos alimenticios.

${ }^{3}$ En Yucatán, el término "mestizo" se utiliza para nombrar a la población indígena y no a la mezcla de indígenas y españoles.
} 
lizarse, ya que para los concesionarios resulta muy importante la asistencia de público proveniente de la ciudad de Mérida y otras localidades aledańas. Muy probablemente en esta perspectiva también contemplan al turismo nacional e internacional.

El mayor número de transformaciones, de acuerdo con los resultados, se han dado en la parte festiva y los menos en la religiosa. De hecho, se considera que los gremios siguen desarrollándose casi igual que en el pasado. Sin embargo, hay menor asistencia a las actividades religiosas y gremiales, lo que representa una preocupación para los responsables de los gremios, ha decrecido el número de sus integrantes, hay poca participación de los jóvenes y adultos jóvenes, y los convivios gremiales antes de la entrada a la iglesia son cada vez más modestos y reducidos numéricamente. Un elemento a destacarse es el desconocimiento o versiones contradictorias en la localidad respecto del número de gremios y su especialidad.

Como se aprecia en las entrevistas a padres y abuelos, la observación etnográfica y los testimonios orales, también está desapareciendo paulatinamente la imagen "tradicional" de la festividad (el uso del hipil, las alpargatas chillonas, el pantalón y filipina blanca y el sombrero entre la concurrencia) y el sentido de constituir un festejo que convoca a la "comunidad" en su conjunto. Para entender estas transformaciones o "pérdidas", no puede dejarse de lado la condición de cultura dominada de los pueblos maya-yucatecos y el impacto de nuevos modos de vida en la comunidad de Conkal derivados del contacto con lo urbano y lo global.

\section{LA INFLUENCIA DE LOS MEDIOS DE COMUNICACIÓN}

El trabajo etnográfico permitió detectar la relación, cada vez más creciente, entre la promoción de las fiestas del pueblo y el uso de medios masivos de comunicación. La radio y el cartel se han constituido en recursos fundamentales de difusión hacia el exterior de la comunidad, mientras que formas tradicionales como el perifoneo (usando autos con altoparlantes) y la transmisión oral lo son hacia el interior.

Sin embargo, el interés de la investigación respecto de los medios masivos de comunicación se concentró en su influencia en las transformaciones y representaciones actuales, detectadas a través de los niños y niñas estudiados. Los resultados muestran con gran claridad la forma como ciertos productos mediáticos están colaborando en la formación de nuevas representaciones cul-

Comunicación masiva - culturas radicionales: $\bullet 395$ un estudio sobre persistencia y transformación en las fiestas del pueblo de Conkal, Yucatán 
turales de los niños y cómo estos cambios impactan su relación con las fiestas del pueblo.

Los datos provienen de las imágenes fotográficas seleccionadas por los niños y niñas, de los dibujos que elaboraron, del cuestionario que contestaron y de las representaciones teatrales que realizaron. En las dos primeras técnicas destaca la presencia de la imagen del dragón, un animal mítico oriental que no forma parte de la cosmovisión maya yucateca, pero que convertido en juego mecánico se constituyó en éxito dentro de las preferencias infantiles, por encima de otros juegos menos novedosos como la rueda de la fortuna, las tazas, los carritos chocones o los futbolitos. La barra televisiva en los últimos años ha privilegiado, por su éxito, la transmisión de caricaturas japonesas que han acercado símbolos orientales a las representaciones actuales de los niños que viven en esta pequeña comunidad y que se manifiestan de forma clara en esta elección masiva.

Además del dragón oriental, en las fiestas del pueblo irrumpen otras prácticas y símbolos culturales contemporáneos, como se desprende del cuestionario aplicado a los niños y niñas. Por ejemplo, aparecen nuevos géneros musicales (pop, música "americana", de banda), nuevos estilos de baile (propios de las fiestas de "luz y sonido"), nuevas vestimentas entre la población. Sin duda, el consumo de medios de comunicación y la industria del entretenimiento impactan especialmente a los niños y jóvenes de Conkal, como lo revela el hecho de que la música de banda, un género musical esencialmente norteño, ha llegado a esta región gracias a la radio y televisión y hoy día está entre sus aficiones.

También, los niños y niñas reconocen que los artistas de la televisión y las películas son agentes de educación informal, ya que junto con sus padres, sus maestros, hermanos y amigos les enseñan a bailar. En sus respuestas no ocupa un lugar importante el aprendizaje de la jarana, aunque la identifican como un baile típico de Yucatán, propio de su cultura y que regularmente lo aprenden en la escuela a través de sus profesores y lo llegan a ejecutar en alguna festividad escolar.

\section{Conclusiones}

La fiesta del pueblo en Conkal, con su histórica estructura festiva y religiosa, ha sobrevivido a las fuertes presiones derivadas del proceso colonial y poscolonial, la modernidad occidental y la globalización. Asimismo ha sobrevivido a los conflictos experimentados al interior de la propia comunidad. La investigación 
ha permitido identificar los diferentes recursos de los que hasta hoy ha dispuesto la comunidad para preservar su fiesta tradicional y gran parte de la riqueza simbólica que la caracteriza; esto la ubica como una de las más importantes prácticas culturales constructoras de identidad en el pueblo de Conkal. Por su capacidad de transformación, la fiesta se revela como una manifestación cultural viva, capaz de cambiar, refuncionalizarse y hacerse contemporánea.

Dentro de las transformaciones experimentadas en las fiestas del pueblo, el consumo y uso social de los medios masivos de comunicación van teniendo un papel significativo, aunque no determinante por el momento. Los resultados de la investigación emiten mensajes de gran importancia para repensar los usos, lecturas y apropiaciones que particularmente las nuevas generaciones están haciendo de la comunicación masiva, a partir de sus prácticas comunicativas, de su experiencia y del sentido que atribuyen a su cultura tradicional y a las nuevas manifestaciones culturales, en las que cotidianamente están creciendo.

No podemos omitir que en estos cambios o transformaciones hay culturas que se imponen sobre otras y esas otras sobreviven en contextos generalmente adversos; este es el caso de las manifestaciones culturales tradicionales. En esta relación de poderes, las industrias culturales empiezan a ocupar paulatinamente un papel central en la configuración del sentido en relación a las fiestas y danzas entre las nuevas generaciones que habitan Conkal, desplazando el papel que hasta hace unos cuantos ańos jugaban la oralidad y la socialización primaria. En los datos proporcionados por los niños y niñas y a través de las técnicas utilizadas aparece la silueta de lo que pronto sucederá: una cada vez mayor interrelación e interdependencia con los medios masivos de comunicación, particularmente por la vía del entretenimiento.

Tampoco podemos cerrar los ojos ante lo que alguna vez dijo García Canclini (1990, pp. 241-242): "En rigor, al mercado y a los medios no les importa lo popular sino la popularidad. No les preocupa guardar lo popular como cultura o tradición (...) Para el mercado y para los medios lo popular no importa como tradición que perdura”. Así, la transmisión de generación en generación de la esencia de las fiestas del pueblo, vía la escuela, la familia y la propia comunidad, se constituye en el punto nodal y en el centro de mayor interés entre los diversos informantes que contribuyeron a desentrañar tan preciado acontecimiento para la vida de este pequeño poblado del sureste mexicano.

Comunicación masiva - culturas radicionales: • 397 un estudio sobre persistencia y transformación en las fiestas del pueblo de Conkal, Yucatán 
BiBLIOGRAFÍA

Bartolomé, M. (1988). La dinámica social de los mayas de Yucatán. Pasado y presente de la situación colonial. México: INI.

Bonfil, G. (1993). Por la diversidad del futuro. En Guillermo Bonfil (comp.). Hacia nuevos modelos de relaciones interculturales. México: CNCA, pp. 222-234.

Cohen, D. (1999). Cómo aprenden los niños. México: SEP / Fondo de Cultura Económica.

Fernández, F. (1990). Resistencia cultural y religiosidad popular. Los gremios en Chuburná de Hidalgo, Mérida, Yucatán. Boletín de la Escuela de Ciencias Antropológicas de la Universidad de Yucatán, Vol.16, No. 101, pp. 20-34

Fernández, F. y Quintal, E. (octubre-noviembre 1992). Fiestas y fiestas. Revista de la Universidad Autónoma de Yucatán, Núm. 183, pp. 39-48.

García-Canclini, N. (1990). Culturas hibridas. Estrategias para entrar y salir de la modernidad. México: Grijalbo.

INEGI (2001). Censo General de Población y Vivienda 2000. México: INEGI.

Irigoyen, R. (1973). Calendario de fiestas tradicionales de Yucatán. Mérida, Yucatán: Ediciones del Gobierno del Estado.

López y Rivas, G. (5 de enero de 2005). Antropología y zapatismo. La Jornada. Recuperado el 14 de enero de 2005 de: http://www.jornada.unam.mx/2005/ ene05/050114/022a1pol.php

Maas, H. (1983). Transmisión cultural en Chemax, Yucatán. Un enfoque etnográfico. Departamento de estudios sobre cultura regional. Mérida, Yucatán: Universidad de Yucatán.

Maas, H. (diciembre de 1995). La religión y símbolos sagrados en la vida cotidiana de las familias campesinas, Huhí, Yucatán. Informe final de investigación. Centro de Investigaciones Regionales-Unidad Ciencias Sociales “Dr. Hideyo Noguchi”, de la Universidad Autónoma de Yucatán. Mérida, Yucatán.

Martín-Barbero, J. (1987). Introducción. En FELAFACS, Comunicación y culturas populares en Latinoamérica. Seminario del Consejo Latinoamericano de Ciencias Sociales. México: Gustavo Gili, pp. 9-17.

Martín-Barbero, J. (1988). De los medios a las mediaciones: Comunicación, cultura y hegemonía. 5ta. ed. México: Gustavo Gili.

Ortiz, R. (1998). El viaje, lo popular y el otro, Otro territorio. Colombia: Convenio Andrés Bello, pp. 1-20.

Quintal, E. (1993). Fiestas y gremios en el oriente de Yucatán. Cuadernos de cultura yucateca. No. 4, pp. 1-49

Redfield, R. (1944) Yucatán: una cultura en transición. México: Fondo de Cultura Económica. 
Thompson, J. B. (octubre de 1991). La comunicación masiva y la cultura moderna. Contribución a una teoría crítica de la ideología, Revista Versión. Estudios de comunicación y política, núm. 1. México: UAM-Xochimilco.

Villanueva, N. (2000). Cultura, identidad de género y simbolización en los juegos infantiles, Temas antropológicos, Vol.22, No.1, pp. 25-53

Villa Rojas, A. (1978). Los elegidos de Dios. Etnografia de los mayas de Quintana Roo. México: Instituto Nacional Indigenista. 